\title{
Towards a Comprehensive View of Object-Oriented Play
}

\author{
Elizabeth R. Wynberg ${ }^{1,2}$ (D) Annerieke Boland ${ }^{1}$ (D) - Maartje E. J. Raijmakers ${ }^{2}$ (D) \\ Chiel van der Veen ${ }^{2}$ (D)
}

Accepted: 15 February 2021 /Published online: 27 April 2021

(C) The Author(s) 2021

\begin{abstract}
The exploration and/or manipulation of objects and materials, referred to as objectoriented play (OOP), is one of the most prominent activities children engage in during early childhood. Especially within early childhood education, it is important to be able to assess and understand OOP, its developmental trajectory, and developmental value. This can support early childhood educators to successfully guide or enrich children's OOP, so it becomes a context in which learning can take place. During the past decades, three dominant theoretical perspectives have explained and assessed certain (developmental) aspects of OOP: (1) genetic epistemology, (2) cultural historical psychology, and (3) evolutionary psychology. After reviewing the literature concerning OOP according to each theoretical perspective, this paper aims to synthesize these existing theories into a unified theoretical framework. This theoretical framework can be a starting point for future research on OOP in early childhood (education). We answer the following research questions: Q1. What are the defining labels and features of the exploration and/or manipulation of objects and materials by children in early childhood?; Q2. What is the developmental trajectory of the exploration and/or manipulation of objects and materials by children in early childhood?; Q3. What is the developmental value of the exploration and/or manipulation of objects and materials by children in early childhood?
\end{abstract}

Keywords Object-oriented play · Manipulation · Exploration · Objects · Materials $\cdot$ Child development

Elizabeth R. Wynberg

E.wynberg@vu.nl

1 University of Applied Sciences iPabo, Jan Tooropstraat 136, 1061 AD, Amsterdam, The Netherlands

2 Faculty of Behavioural and Movement Sciences, Section of Educational Sciences, and LEARN! Research Institute, Vrije Universiteit Amsterdam, Van der Boechorststraat 7, 1081 BTAmsterdam, The Netherlands 
Bobby (18 months) has a new bottle. He visually inspects it while rotating it in his hands a few times. Next, he gives the nipple of the bottle a squeeze and turns the bottle upside down. As he does this, some milk spurts from the nipple, making him giggle. He repeats this a couple of times. When I ask Bobby if he likes his milk, he looks at me and starts drinking. After a couple of sips, Bobby takes the nipple out of his mouth and again squeezes the nipple of the bottle between his fingers. He starts drinking again but this time he stops to present the bottle to me, indicating he wants me to drink from it. I pretend to take a sip and this elicits an enormous grin from Bobby. He repeats this scenario a couple of times again. Each time, he is even more pleased when I pretend to sip, which he shows by increasing giggles. Once the bottle is finished, Bobby manages to twist off the top. He grabs a small spoon from the table, puts it inside the bottle, and tries to close the bottle. Then he holds out the bottle towards me. I take this as an indication that he wants me to help him close it. He watches closely as I twist on the top. Afterwards, he grabs the bottle and starts shaking it, so it makes a sound. Bobby proceeds to repeat this whole sequence a couple of times: Taking the bottle apart and putting it back together by twisting the top, each time giving it a little shake to make a noise once it is closed.

This example illustrates a moment of Bobby's engagement with his environment: a bottle, a tiny spoon, and his childhood educator, the first author of this paper. This behavioral phenomenon is not special or specific to Bobby: All children and most mammals explore and manipulate objects and materials in their environment (Ellis 1973; Power 2000). It has been pervasive throughout our evolution as a human species and is seen across different cultures (Bjorklund and Gardiner 2011; Göncü et al. 2000; Riede et al. 2018). Synthesizing a theoretical framework for this universal and pervasive behavioral phenomenon will be the focus of this paper.

The exploration and/or manipulation of objects and materials is one of the most prominent activities children engage in during early childhood, with a peak between the ages of approximately 18 months until 3.5 years. Children are naturally attracted to objects in their environment (Lewin 1931). Once children have developed the necessary physical capabilities, they will start to explore and manipulate objects (and materials) to discover the physical properties of the object does and what they can do with the object (Bjorklund and Gardiner 2011; Lewin 1931; Power 2000). After early childhood, it continues to be an important part of human behavior, especially when a child or adult is presented with new objects and materials (Berlyne 1960; Ellis 1973; El'konin 1978; Lockman and McHale 1989).

The behavior or activity of exploring and/or manipulating objects and materials is very diverse: It can take on many forms, involve different developmental domains, and occur in various contexts. For example, during exploring or manipulating, one can observe that children relate or combine two or more objects to each other; sort, group, or stack objects or materials; or substitute one object for another. These behaviors each involve different developmental domains, such as cognition, motor skills, and social interaction; can show important developmental changes over time, such as the progression from manipulating one object to two or more objects in relation to each other (Casby 2003; Vig 2007); and occur (naturally) in many different contexts, such as at home, when playing outside, or in an educational setting.

In early childhood education, the exploration and/or manipulation of objects and materials is often referred to as a form of play. Across all play literature, scholars agree on the difficulty of defining play. In an extensive review, Rubin et al. (1983) summarized and compared all 
major play theories. They concluded that all approaches that attempted to define play shared the notion that "play is a behavioral disposition that occurs in describable and reproducible contexts and is manifest in a variety of observable behaviors" (p. 689). Rubin et al. (1983) also distilled four dispositions that apply to play in general: (1) being highly involved, (2) intrinsically motivated for the sake of play(ing), (3) deriving pleasure from it, and (4) having the freedom to modify the rules within the play (Rubin et al. 1983). These four dispositions provide us with a consensual working definition of play and specify the behavior of interest, especially when we assess this behavior in the context of early childhood education. For the purpose of this paper, we will include all behaviors that can be classified as a child's exploration and/or manipulation of objects and materials while being highly involved, intrinsically motivated, deriving pleasure from it, and having the freedom to modify the rules (cf., Rubin et al. 1983).

Especially within early childhood education, it is important to assess and understand children's exploration and/or manipulation of objects and materials, its developmental trajectory and developmental value. We argue that being able to assess and understand this behavior provides support to early childhood educators in successfully guiding or enriching this behavior, so it becomes a context in which learning can take place (van Schijndel et al. 2010). A firm theoretical understanding and comprehensive view of this behavior can support educators to observe, assess, and guide children's exploration and/or manipulation of object and materials. Unfortunately, to date, no comprehensive theoretical framework exists to explain and assess the exploration and/or manipulation of objects and materials, despite its universality, pervasiveness, and potential developmental value. Nonetheless, many theories (and empirical studies) have devoted some effort to explain or understand certain aspects of this behavioral phenomenon (e.g., El'konin 1978; Pellegrini 2009; Piaget 1967/1951). Therefore, in this paper, we aim to synthesize these existing theories into a unified theoretical framework.

In the literature on play, we can roughly distinguish three well-known theoretical perspectives that have explained and assessed certain (developmental) aspects of the exploration and/ or manipulation of objects and materials. These perspectives are (1) genetic epistemology, (2) cultural historical psychology, and (3) evolutionary psychology. All three perspectives have been developed independently by separate communities of researchers and focused on different aspects of this behavior. Furthermore, the three perspectives differ in research focus, productivity, and methodology. Consequently, the researchers within each perspective proceeded to develop their own defining labels and features, their own particular view on its developmental trajectory, and considered it to be of value to different developmental domains (Athey 1984). Thus, the interpretation of this behavioral phenomenon, its developmental trajectory and the developmental value ascribed to it, depends heavily on the theoretical considerations of the interpreter (Rubin et al. 1983).

Assessing this behavioral phenomenon by considering only one theoretical perspective can lead to an incomplete view of its behavioral features and developmental trajectory. Moreover, it might cause the relations between different domains of development to be overlooked and might lead to an inadequate view of the developmental value of exploring and/or manipulating objects and materials, since all aspects of development stand in relation to one another (Demetriou et al. 2011). Therefore, to fully comprehend and adequately assess this behavioral phenomenon as well as its developmental trajectory and value, a comprehensive theoretical framework is necessary and would provide an important contribution to the field of childhood education and research on play. 
The theoretical framework synthesized in this paper can be used to inform early childhood education and future research on children's exploration, physical and mental manipulation of objects in early childhood, and sheds light on its developmental trajectory and developmental value (i.e., the function of the behavior for purposeful actions, the development, or the wellbeing of the subject). By reviewing the three theoretical perspectives on their interpretation of this behavioral phenomenon, we can firstly ensure that all behaviors, features, and relevant ideas concerning this behavioral phenomenon, its developmental trajectory, and developmental value are included. Secondly, we can compare the ideas presented within each perspective to see what similarities can enhance each other or which differences can complement each other.

By discussing, comparing, and integrating the ideas advanced within the three different theoretical perspectives mentioned earlier, this synthesis should provide insight into the following research questions:

Q1. What are the defining labels and features of the exploration and/or manipulation of objects and materials by children in early childhood?

Q2. What is the developmental trajectory of the exploration and/or manipulation of objects and materials by children in early childhood?

Q3. What is the developmental value of the exploration and/or manipulation of objects and materials by children in early childhood?

In the next part of this paper, we will first review the literature concerning the exploration and/ or manipulation of objects and materials according to each theoretical perspective. In doing so, we will divide the discussion of each perspective into three subsections following the research questions outlined above: Q1, Q2, and Q3 (see Table 1 for an overview of the main concepts discussed per perspective). Finally, we will discuss, compare, and integrate the ideas from these perspectives to give a comprehensive answer to our three research questions.

\section{A Genetic Epistemological Interpretation of the Exploration and/or Manipulation of Objects and Materials}

The first theoretical perspective, genetic epistemology, was established by Piaget in the middle of the 20th century in Switzerland. This perspective focuses on explaining the process of cognitive development, by tracing the origin of knowledge. Knowledge consists of structures and stems from the adaptation of these structures to their environment (through social exchange), referred to as equilibration (Byrnes 2008). As knowledge starts with innate motor skills, children's sensorimotor interactions with objects are the root of cognitive development.

\section{The Defining Labels and Features of Children's Exploration and/or Manipulation of Objects and Materials}

According to a genetic epistemological interpretation, Bobby's behavior, described in the introductory example, would be labelled play. Play is viewed as a general exercise of activities at a given developmental level without present utility (Piaget 1967/1951). However, what type of play it would be labelled as depends on which theorist is referred to, since the view on play within this perspective has evolved over time. Piaget would have referred to it as practice play: 
Table 1 Overview of the three discussed perspectives

\begin{tabular}{|c|c|c|c|}
\hline & Genetic epistemology & $\begin{array}{l}\text { Cultural historical } \\
\text { psychology }\end{array}$ & Evolutionary psychology \\
\hline $\begin{array}{l}\text { Defining labels for the } \\
\text { exploration and/or ma- } \\
\text { nipulation of objects and } \\
\text { materials }\end{array}$ & $\begin{array}{l}\text { Practice/functional play } \\
\text { Exploratory sensorimotor } \\
\text { play } \\
\text { Relational-nonfunctional } \\
\text { play } \\
\text { Functional-conventional } \\
\text { play } \\
\text { Constructive play } \\
\text { (creative) }\end{array}$ & $\begin{array}{l}\text { Exploratory orientation } \\
\text { Manipulative play }\end{array}$ & $\begin{array}{l}\text { Exploration } \\
\text { Object play } \\
\text { Tool use } \\
\text { (Construction) }\end{array}$ \\
\hline $\begin{array}{l}\text { Defining features and } \\
\text { mechanisms through } \\
\text { which the exploration } \\
\text { and/or manipulation of } \\
\text { objects and materials } \\
\text { develops }\end{array}$ & $\begin{array}{l}\text { Repetition } \\
\text { Imitation } \\
\text { Assimilation } \\
\text { Accommodation }\end{array}$ & $\begin{array}{l}\text { Child-caregiver joint } \\
\quad \text { attention } \\
\text { Mediation } \\
\text { Zone of proximal } \\
\quad \text { development } \\
\text { Imitation } \\
\text { Repetition } \\
\text { Association }\end{array}$ & $\begin{array}{l}\text { Child-caregiver joint } \\
\quad \text { attention } \\
\text { Stimulus enhancement } \\
\text { Emulation } \\
\text { Imitation }\end{array}$ \\
\hline $\begin{array}{l}\text { The developmental } \\
\text { trajectory of the } \\
\text { exploration and/or ma- } \\
\text { nipulation of objects and } \\
\text { materials }\end{array}$ & $\begin{array}{l}\text { Simple reflexes } \rightarrow \\
\text { primary circular } \\
\text { reactions } \rightarrow \text { secondary } \\
\text { circular reactions } \rightarrow \\
\text { coordination of } \\
\text { secondary circular } \\
\text { reactions } \rightarrow \text { tertiary } \\
\text { circular reactions } \rightarrow \\
\text { early symbolic thought }\end{array}$ & $\begin{array}{l}\text { Emotional interaction } \\
\text { with caregiver } \rightarrow \\
\text { child-caregiver joint } \\
\text { object-centered } \\
\text { activity/manipulative } \\
\text { play } \rightarrow \text { substitution of } \\
\text { objects } \rightarrow \\
\text { sociodramatic play }\end{array}$ & $\begin{array}{l}\text { Object understanding } \rightarrow \\
\text { dyadic imperative } \\
\text { interactions } \\
\text { (exploration) } \rightarrow \\
\text { 9-month revolution } \rightarrow \\
\text { triadic declarative inter- } \\
\text { actions } \rightarrow \text { object } \\
\text { play/tool use/(- } \\
\text { construction) } \rightarrow \text { object } \\
\text { substitution } \rightarrow \\
\text { symbolic/pretend play }\end{array}$ \\
\hline $\begin{array}{l}\text { Developmental value of the } \\
\text { exploration and/or ma- } \\
\text { nipulation of objects and } \\
\text { materials }\end{array}$ & $\begin{array}{l}\text { (Sensori)motor } \\
\quad \text { development } \\
\text { Cognitive development } \\
\text { - Schemes }\end{array}$ & $\begin{array}{l}\text { Driving force of } \\
\text { development } \\
\text { Speech and symbolic } \\
\text { thought }\end{array}$ & $\begin{array}{l}\text { Adaptation } \\
\text { Social cognition } \\
\text { Tool use }\end{array}$ \\
\hline
\end{tabular}

the repetition of already acquired behavior, detached from its function, purely for the joy of practicing and mastering it (Piaget 1967/1951). Practice play often, but not always, involves one or more objects. This is visible for example when Bobby repeatedly twists the top of the bottle off and on. This repetition of behavior is a key defining feature of practice play (Piaget 1967/1951).

Smilansky (1968) basically agreed with Piaget, although she would label this repetitive twisting of the top of the bottle as functional play, with the defining features being both imitation and repetition. Bobby sees his childhood educator twisting off the top of the bottle, after which he imitates and repeats this action. Besides, Smilansky would also argue that there is an element of constructive play-i.e., engaging in creative activities while learning the various uses of objects and materials - in Bobby's behavior. By putting the spoon in the bottle, Bobby "created" an object that makes noise.

Casby (2003) further specified the different levels he recognized within practice/functional play. Depending on which specific behavior within the example is considered, he would divide Bobby's behavior into three (out of four, the fourth being symbolic play) different categories: (1) exploratory sensorimotor play—-physically manipulating and inspecting objects - when 
Bobby rotates the bottle or squeezes the nipple of the bottle; (2) relational-nonfunctional play - relating two or more objects without adhering to the function of the objects-when Bobby puts the spoon inside the bottle; and (3) functional-conventional play - using the object according to its "cultural" function-when Bobby puts the top on the bottle or offers a drink from it. Casby (2003) distinguished these different levels based on his review of applied research that followed Piaget's work.

As the interchangeable labels (i.e., practice play and functional play) indicate, within the genetic epistemology perspective children's exploration and/or manipulation of objects and materials is considered practice for different aspects of a child's development or, as Smilansky (1968) would say, it is functional to a child's development. Both labels can be subdivided into exploratory sensorimotor play, relational-nonfunctional play, and functional-conventional play (Casby 2003). Imitation and repetition, as the main features of both practice and functional play, ensure the progression of play through the aforementioned hierarchical levels. Finally, constructive play, as proposed by Smilansky (1968), should be considered as a separate term and behavior that indicates when children start creating things with objects and materials within their play.

\section{The Developmental Trajectory of Children's Exploration and/or Manipulation of Objects and Materials}

A central idea within the genetic epistemological perspective is that cognition, and corresponding behavior, develops through stages and always progresses from simple to more complex (Brainerd 1978; Fischer 1980; Piaget 1970). The four stages distinguished by Piaget (1967/1951) are (1) the sensorimotor stage (around 0 to 2 years), (2) the preoperational stage (around 2 to 6 years), (3) the concrete operational stage (around 6 to 11 years), and (4) the formal operational stage (older than 11 years).

Each developmental stage has its distinct play component, since play is acknowledged as a reflection of a child's cognitive development (Piaget 1967/1951; Casby 2003). Therefore, specific behaviors of children during play are indicative of their current level of cognitive development. Practice play (involving objects) is seen as the component of the sensorimotor stage. Children's development starts with the first interactions between subject and object during the sensorimotor stage, as cognitive development is rooted in sensorimotor knowledge. Initially, newborns are incapable of making a distinction between themselves and their surroundings (e.g., people or objects). During the sensorimotor stage, they discover this distinction and what this means for their own actions.

Piaget (1967/1951) distinguished six additional substages of sensorimotor intelligence (Brainerd 1978). These substages of the sensorimotor stage are (1) simple innate reflexes (around the first month of a child's life), (2) primary circular reactions (1-4 months): repeating a pleasurable and self-reinforcing action involving one's own body, (3) secondary circular reactions (4-8 months): intentionally repeating an action involving a one's own body and/or an object to elicit a response, (4) coordination of secondary schemes (8-12 months): using gained knowledge to reach a certain goal and having clear intentional actions, (5) tertiary circular reactions (12-18 months): the (systematic) experimentation with actions and schemes to intentionally adapt to specific situations, and (6) early symbolic thought (after 18 months).

The substages of the sensorimotor stage describe how Piaget (1967/1951) viewed the development of the interaction between subject and object throughout the sensorimotor stage and therefore also portray the developmental trajectory of practice play. Once children start to 
engage in primary circular reactions, their behavior would be classified as practice play (Piaget 1967/1951). From here, the child's interactions with objects during practice play evolve into more complex (motor and cognitive) interactions advancing through the different substages until the child arrives at early symbolic thought. The stage of early symbolic thought is the transitional phase to the preoperational stage with its play component: symbolic play.

Throughout children's early development, the progressive coordination of information provided by physical experience, maturation, and voluntary practice brings about the qualitative transformations of a child's schemes (Case 1985; Fischer 1980; Piaget 1970). These schemes are patterns of mental representations, also referred to as cognitive structures, that organize information (Piaget 1970). Progressive coordination is the result of a child's assimilation and accommodation of these cognitive schemes (Byrnes 2008; Inhelder 1971). When children are assimilating, they interpret new experiences according to their already acquired cognitive schemes. When children are accommodating, they adjust the acquired schemes to fit the new experience (i.e., imitation). Restoring the balance (referred to as equilibrium in Piaget's work) between assimilation and accommodation leads to cognitive behaviors of intelligence (Byrnes 2008). In practice play, the newly acquired behaviors and cognitive schemes are consolidated through imitation and repetition.

Smilansky (1968), in line with Piaget, also viewed development as a sequence of stages. Although her idea of stages in cognitive development was less rigid, practice/functional play progresses to constructive play when manipulation (defined as simple muscular activities with objects) progresses to formation (defined as creative activities with the objects). Smilansky (1968) concluded that the stages can overlap quite extensively, even to the point where children exhibit behaviors indicative of two stages at the same time. However, at any given time, one of the stages is always dominant in children's development; thus, there is a sequential order to these developmental stages (Smilansky 1968). This sequential order also becomes apparent in Casby's (2003) proposed hierarchical categories of practice play, starting with exploratory sensory motor play, evolving into relational-nonfunctional play, then functional-conventional play, and eventually leading to the next stage of symbolic play (see previous section for an explanation of Casby's categories of play).

\section{The Developmental Value of Children's Exploration and/or Manipulation of Objects and Materials}

\section{(Sensori)motor Development}

In genetic epistemology, children's exploration and/or manipulation of objects and materials is considered important for their (sensori)motor development. Practice play, as a component of the sensorimotor stage, refers to the practice and mastering of specific motor skills for the joy of mastering it. In Piaget's (1967/1951) subdivision of the sensorimotor stage, he focuses on the different motor developments that create new possibilities for the child, starting with the simple motor reflex. The primary circular reactions involve motor skills such as grasping, allowing for certain object manipulations. The secondary circular reactions refer to motor actions involving the body or an object that can elicit a response in the environment. Once children start coordinating these secondary circular reactions, they can use their acquired motor skills to reach a goal (Piaget 1967/1951) definition of practice/functional play-simple muscular activities driven by the need to activate certain physical domains - also demonstrates how play, in turn, contributes to the practice of certain motor skills. 


\section{Cognitive Development}

The importance of the interaction with objects in a child's development was firmly established in Piaget's theory (1970). He argued that children's cognitive development is rooted in their sensorimotor interactions with objects and that, in order to gain information about objects, the subject (i.e., the child) must act upon them and transform them (Piaget 1970; Inhelder 1971). In our example, Bobby is practicing twisting the top of the bottle off and on. Through the repetition of that manipulation, twisting the top off and on becomes detached from its function. The subject, Bobby, is learning about the affordances of the object by engaging with it through practice play, which according to Piaget might contribute to his cognitive development.

Schemes During practice play, children start to develop their first schemes (i.e., psychological structures), which are considered the building blocks for cognitive development. The assimilation of information into a scheme supports children to organize and interpret this information (Piaget 1970). The development of schemes starts during the substage of secondary circular reactions, when a child intentionally repeats an action. Through repetition, characteristic for practice play, these schemes become familiar and ritualized until a child can coordinate multiple actions or schemes and eventually reaches the next substage. Children's schemes keep evolving due to gradual qualitative coordination (assimilation and accommodation) through all the substages and eventually will enable children to form symbolic representations (Athey 2013).

\section{Concluding Remarks}

From what we have discussed in this section, it becomes clear that the genetic epistemology perspective emphasizes the role of the exploration and/or manipulation of objects and materials in the construction of knowledge. See Table 1 for an overview of the main concepts and ideas of this perspective. Although Piaget's stages of cognitive development and accompanying stages of play received some criticism early on (see for example papers by Driver (1978) and Sutton-Smith (1966)), his theory is still used in some cases, for example to chart developmental change and as a framework for prescriptive play therapy (Kaduson 2015; Lourenço 2016). Moreover, many play-based activities and education curricula currently underscore the importance of supporting children's cognitive schemes (Atherton and Nutbrown 2013; Arnold 2013; Athey 2013).

\section{A Cultural Historical Psychological Interpretation of the Exploration and/ or Manipulation of Objects and Materials}

Vygotsky ${ }^{1}$ - together with his colleague Lurija — established the cultural historical psychology perspective around the middle of the 20th century in the former Soviet Union. This theory focuses on learning as a social and cultural process. Children's behavior and development is

\footnotetext{
${ }^{1}$ Vygotskij is a more consistent translation of his name in Russian. However, he is usually referred to as Vygotsky in Anglo-Saxon translations. As to not create any confusion when referencing, we spelled his name as Vygotsky in this paper.
} 
influenced and promoted by their surrounding culture and environment. In turn, throughout children's development, they will become a member of this culture and (critically) contribute to the evolvement of this culture through the mediation of their surroundings.

\section{The Defining Labels and Features of Children's Exploration and/or Manipulation of Objects and Materials}

According to a cultural historical psychological interpretation, Bobby and his childhood educator are engaged in child-caregiver joint object-centered activity. This develops when a child is between the ages of 1 and 3 years old. During this period, often whilst engaged in joint attention with their caregiver(s), children explore the physical and social reality surrounding them and manipulate their environment to experience the effects of their manipulations (El'konin 1978). This exploration is, in essence, a child's orientation within their reality (Gal'perin 1980). Podd'jakov (1979) subdivided children's manipulations into two types: (1) exploration (and manipulation) to learn about the characteristics of the object and (2) manipulation of the objects' characteristics and relations, to elicit a practical effect.

Within this perspective, it is essential that the manipulative activity is meaningful to the child itself, so there is an opportunity for learning to take place. Participating in an activity can either optimize our current action(s) or create opportunities for teaching us new actions (Van Oers 2010). Specifically, the activity of exploring and/or manipulating objects can lead to the emergence of new needs. By exploring or manipulating the object, a child can discover new affordances of the object or possible actions with the object which can instigate curiosity. This can be the impulse to change actions and provides an opportunity to learn.

Bobby's exploration and/or manipulation of objects during this child-caregiver joint objectcentered activity is also referred to as play, in this case manipulative play. Manipulative play can refer to any concrete action with (an) object(s): e.g., banging or throwing an object, stacking, grouping, sorting, or nesting multiple objects. A defining feature of this type of play is its associative nature, as the activity often flows from one type of manipulation of the object into the next without a presupposed plan. When Bobby twists the top off, this allows for putting something (the spoon) inside of it. This, in turn, gives him the idea to shake the bottle. During this play activity, Bobby also repeats several of his behaviors, which is another defining feature of manipulative play.

Play should not be regarded as a distinct activity separate from other cultural activities such as learning or working, according to Van Oers (2012, 2013). Based on the earlier work of Vygotsky (1933/1967) and El'konin (1978), Van Oers (2013) developed a play theory in which he conceptualizes play as a mode of activity. Any cultural activity is or can be formatted as play when it is performed in a "play format." The play format is based on the values of three interrelated parameters: (1) involvement, (2) rules, and (3) degrees of freedom.

Cultural activities have the format of play when children are highly involved and can enter the play activity voluntarily; are either implicitly or explicitly following or guided by rules (such as technical rules or social rules); and have sufficient degrees of freedom to make their own choices regarding their actions, goals, rules, or use of tools within the activity (Van Oers 2013). Using a cultural historical psychology lens, we can understand Bobby's exploration and/or manipulation of objects to be manipulative play: He voluntarily chooses to start this activity and is highly involved, he has degrees of freedom to manipulate any certain object in any certain way (e.g., squeezing, drinking, shaking, or twisting), while this is governed by the 
rules of the object or surroundings (e.g., the nipple is soft and supple, the top can be twisted off, and it is used according to its cultural function of drinking).

\section{The Developmental Trajectory of Children's Exploration and/or Manipulation of Objects and Materials}

The cultural historical psychology perspective makes a distinction between the exploration and/or manipulation of objects during the first year and the second year of life. During the first year of life, children explore (and manipulate) objects according to the physical characteristics of these objects. This persists into exist in the second year. However, during this second year, another type of object activity develops, namely the manipulation of objects to attain a practical goal and the manipulation of objects according to their social meanings. To discover these social meanings, children are dependent on their surroundings (Karpov 2003). At this point, the manipulations serve the child's orientation as a cultural activity instead of the reflex it started out as (Gal'perin 1980). This change of activity, around the end of the first year of life, starts with children imitating their caregiver(s) actions with objects during joint attention, often encouraged by their caregiver(s). Because of these joint activities, children's nonspecific exploration (e.g., banging or shaking) of objects decreases and they start to imitate manipulations without encouragement. These two types of "manipulative thought," exploring the characteristics of objects without pursuing a practical goal and manipulating objects according to their social meaning or to attain a practical goal, are not separable in their pure forms but are closely interrelated (Podd'jakov 1979).

This distinction between the exploration and/or manipulation of objects between the first and second year of life is congruent with the leading activities that are significant for each of those age periods. As part of a group of former pupils of Vygotsky, El'konin and Leont'ev advanced the notion of leading activities in children's development (Fleer and Veresov 2018). In each developmental period, there is a leading activity, determined by society and driven by leading motives, that plays a dominant role in the child's (mental) development (El'konin 1971; Leont'ev, 1972/1981). At each given point in a child's life, certain types of activities will be more prominent and more significant to the development of the child than other activities. These dominant activities characterize that specific phase of development. The transition from one phase of a dominant activity to the next is caused by a shift in the dominance of the relationship the child has to their surroundings (Leont'ev 1965).

During the first year of life, the leading activity is emotional interaction with caregivers. While engaged in emotional interaction, the caregiver will draw the attention of the child to objects through manipulations of these objects. This mediation by the caregiver turns the child's actions into child-caregiver joint object-centered activity, often referred to as manipulative play. Manipulative play then becomes the new leading motive during the second and third year of life (El'konin 1978).

While engaged in manipulative play, children will start to transfer acquired manipulations to new objects, thus learning about the possibility of substituting objects: using an object for something else than what it is intended for (e.g., using a stick as a spoon). The substitution of objects is mediated by language (see the section on language and symbolic thought) and adults. Adults first need to model the procedure of substitution for the child to acquire, master, and internalize it. The mediation by adults and language prepares for the transition to the next leading activity: sociodramatic play (El'konin 1978). 
The development of children's play activities in general can also be observed in either an increase of the number of rules or the complexity of rules during play (Van Oers 2013). Based upon El'konin's notion of rules during role play, Van Oers distinguishes between the following types of rules during play in general: social rules on how to interact with each other and how to perform sociocultural roles; technical rules that refer to the rules of the object itself and how to use the object; conceptual rules that indicate how concepts are formulated; and strategic rules that support the course of the activity. Especially conceptual and strategic rules are more complex and therefore indicate a more matured form of play such as symbolic/role play.

\section{The Developmental Value of Children's Exploration and/or Manipulation of Objects and Materials}

\section{The Driving Force of Development}

Within the cultural historical psychology perspective, manipulative play is regarded as a driving force of development, at least in the preschool years (Vygotsky, 1933/1967). Vygotsky believed that play in general ensures the change in the relationship young children have to their surroundings, from unmediated to mediated.

Based on Vygotsky's notion of mediation, Leont'ev (1978) argued that mediation during manipulative play is an important mechanism for children's development, existing of two interconnected components. Firstly, adults surrounding the child mediate the child's acquisition and mastery of new psychological tools (e.g., language): the inter-psychological component. Secondly, the procedure (the culturally determined way of "using" the psychological tool) of these psychological tools is internalized by the child and comes to mediate the child's mental processes: the intra-psychological component (Karpov 2005). As the first mediating component, the adult models the procedure on how to use a certain psychological tool, after which the adult involves the child in the procedure. Next, the adult slowly withdraws from the procedure until the procedure mediates the child's mental process. In our example, the childhood educator models how to twist off the top of the bottle and involves Bobby by directing his attention to this procedure. She then proceeds to let Bobby try twisting the top by himself. He learns he can twist off the top which opens up new possibilities: The procedure of twisting the top comes to mediate Bobby's mental process.

Every point of mediation comprises of two criteria: the actual development level and the level of potential development. The distance between these two levels is what Vygotsky referred to as the "Zone of Proximal Development." In this zone of proximal development, an essential mechanism is imitation (Van Oers 2011). Through imitation, the adult and the child come to a joint understanding of the cultural activity in which they are engaged. Play emerges due to a tension between current desires of a child and the inability to satisfy these desires. Due to this tension, play has the potential to create a zone of proximal development (Vygotsky, 1933/1967; Rubin et al. 1983).

Manipulative play, specifically, is a source for children's development because a child learns about the objects in their surroundings through the exploration and/or manipulation of these objects. During manipulative play, two types of manipulative knowledge develop: (1) knowledge regarding object characteristics and (2) knowledge concerning the practical possibilities and relations of the object (Podd'jakov 1979). The exploration and/or manipulation of objects and materials during emotional interactions with a caregiver 
teaches a child about the physical characteristics of an object. A child starts to learn how to manipulate the object according to their social meaning during child-caregiver joint object-centered activity, once this becomes the new leading activity (Karpov 2005).

Moreover, through the typical repetition and association seen in manipulative play, children can learn about the rules (affordances) of an object and the effects of their manipulations (Van Oers 2010). According to Van Oers (2010), learning is inherently linked to any activity, including the activities formatted as play. Based on a definition of learning by Van Parreren (1971), Van Oers defines learning as the process of qualitative change of actions or the habituation of existing actions and considers learning to be intrinsic to any cultural activity. He identified four developmental trajectories rooted in manipulative play: the development of social-emotional stability, motor skills, communication skills, and cognitive development (Van Oers 2010).

\section{Symbolic Thought and Speech}

According to the cultural historical psychology perspective, both objects themselves and manipulative play with these objects are important factors in the development of two cognitive domains that are inherently linked to each other: symbolic thought and speech.

Firstly, the impact of objects on symbolic thought was made apparent by Vygotsky (1933/1967). Vygotsky assumed that objects dictate the child's actions at the beginning of development (Vygotsky 1933/1967). When a child is around 1 year old, objects are linked to a symbol: the word denoting the social function of the object. This social function subsequently dictates the child's actions. Only after the age of 3, do objects lose their motivational force to determine the child's actions. At this point, a child has the cognitive ability to create an imaginary situation (Vygotsky 1933/1967).

In an imaginary situation, objects and their meaning can be separated from each other. A child will start to transfer their object-centered actions to new objects. In this process of initiating object substitution, the object's meaning is separated from the object itself (El'konin 1989). This severance between the object and its social meaning within a play context is mediated by its symbol (i.e., speech). At first, a child will still use the actual symbol for the object while using it according to the social meaning of another object (e.g., stirring the pot with a stick, while still referring to it as a stick). Later, a child will name the substituted object by what it is representing (e.g., stirring the pot with a "substituted" spoon). Once they start to refer to the stick with the symbol for what it is supposed to represent, in this case a spoon, a pivot is created to sever the meaning from the immediate experience (Rubin et al. 1983). Now, the actions of a child are determined by the meaning of the symbol and not the object itself. This mediation thus alters the psychological structure determining the relationship of the child to reality: Now a stick can serve as a spoon to stir with (Vygotsky, 1933/1967).

Secondly, the impact of manipulative play on speech was further established by El'konin (1989). During manipulative play, the child is not just engaged in an emotional dialogue with their caregiver, but there is also an object involved. Because of the involvement of an object, manipulative play requires new means of communication and stimulates the development of the child's active speech (El'konin 1989; Karpov 2003). This starts as gestural communication (e.g., pointing to an object) and evolves into verbal communication (e.g., using the word assigned to an object). Speech, subsequently, comes to mediate the child's actions in two ways. First, children will start to use their verbal skills for 
private speech, to regulate their own behavior. Secondly, this private speech becomes self-regulation once it is internalized as a psychological tool (Karpov 2003, 2005).

\section{Concluding Remarks}

The cultural historical psychology perspective places a clear emphasis on the role of the mediating environment concerning the exploration and/or manipulation of objects and materials. This behavioral phenomenon is seen as an important part of both the development and the culturalization of children. See Table 1 for an overview of the main concepts and ideas of this perspective. In current research and literature, the ideas brought forth within the cultural historical psychology perspective still play an important role, especially when it comes to guided play in early childhood education (Bodrova and Leong 2006; Weisberg et al. 2016).

\section{An Evolutionary Psychological Interpretation of the Exploration and/or Manipulation of Objects and Materials}

The final perspective that we will discuss in this paper, evolutionary psychology, is an interdisciplinary perspective that is concerned with the evolution of human physiology and behavior, by studying both humans and nonhumans (e.g., primates). Behaviors are often classified according to the physiological features that accompany the behavior and there is a particular focus on the importance of certain behaviors for development and even for our evolution as a species.

\section{The Defining Labels and Features of Children's Exploration and/or Manipulation of Objects and Materials}

The evolutionary psychology perspective distinguishes the exploration and/or manipulation into several different behaviors based on their difference in physiological features, developmental histories, and developmental consequences (Pellegrini 2009). Different moments of Bobby's behavior, in our example, would be labeled as either exploration, object play, or tool use. These three behaviors are also found in other species such as primates (Power 2000; Vandenberg 1978).

Exploration refers to the manipulation of an object with the aim of discovering the objects' properties and attributes. When Bobby is looking at the bottle and squeezing the nipple, he is exploring the rubbery property of the nipple. Within this perspective, exploration is seen as a specific type of behavior, defined by the physiological features of an elevated heart rate, low distractibility, and negative/flat affect. Animal species, in particular, engage in this behavior to gather information that can reduce uncertainty about their external environment (Power 2000). Children mainly engage in in exploration upon their first encounter with new objects or materials; this decreases overall during childhood or the juvenile period (Hutt 1966; Power 2000). Exploration always precedes other interactions with objects, such as object play: Exploration is a necessary, albeit insufficient, condition for play (Belsky and Most 1981; Hutt 1966; Pellegrini 2009).

Object play (by humans or other species such as primates) is the voluntary, nonfunctional interaction with an object. A critical defining feature of object play is its purposelessness and focus on means over end, as well as repetition, segmentation, sequential variation, and 
exaggeration (Bjorklund and Pellegrini 2002; Pellegrini 2009; Power 2000). Pellegrini (2009) stated that most object play involves pretending with an object. This starts with a child imitating someone else's use of objects and evolves into more abstract behaviors with these objects. Another important characteristic is that children often use objects in various new ways (Pellegrini and Hou 2011). Bobby is engaged in object play when he presents the bottle to me and giggles when I pretend to drink from it. Object play's defining physiological features are a lower heart rate, high distractibility, and a display of positive affect (Hutt 1966).

Tool use refers to the instrumental use of an object, such as using an object in service of a goal or to access resources (Bjorklund and Pellegrini 2002; Pellegrini and Gustafson 2005; Power 2000). When Bobby drinks from the bottle, this would be classified as tool use, as he is using the object to drink. In evolutionary psychology, researchers differentiate between tool use as a convergent activity and making tools as a divergent activity. Although children start to use tools at an early age, children are not very apt at making tools as a divergent activity, which entails more creative ways of using an object to solve a problem (Nielsen et al. 2014; Pellegrini 2013). For humans, tool use also involves learning about the cultural/intentional functions of objects and often results in children (over)-imitating their surroundings. Primates, on the other hand, tend to focus on the instrumental functionality of an object or tool (Ruiz and Santos 2013).

Lastly, there is another label within the evolutionary psychology perspective that could apply to the exploration and/or manipulation of objects and materials, namely construction. However, within this perspective, construction is seen as a behavioral interaction with objects that is accommodative and concerned with the end product more so than with the manipulation of the objects itself. It also occurs later in a child's development (between 3 and 5 years) than the other behaviors mentioned earlier (Pellegrini 2013). Bobby, in our example, is not engaged in this behavior and he would not develop this behavior until he is a little older.

\section{The Developmental Trajectory of Children's Exploration and/or Manipulation of Objects and Materials}

Children will start to explore and manipulate objects once they have developed the necessary physical capabilities (Bjorklund and Gardiner 2011). Pellegrini and many of his colleagues (i.e., Hutt 1966; Bjorklund and Pellegrini 2002; Belsky and Most 1981; Pellegrini and Gustafson 2005; \& Pellegrini and Hou 2011) believe that the exploration of objects always precedes other interactions with objects. Exploration develops around 7-10 months of age and declines afterwards (Pellegrini and Hou 2011). After exploration, object play develops when children are between 1 and 5 years old and then declines. For tool use, there is a less rigid age range established: It develops somewhere during infancy-childhood (Pellegrini 2013).

Vandenberg (1978) proposed a similar sequence of behavioral occurrences in animals, namely an exploration-play-application sequence. New objects are first explored and when deemed safe and familiar, the animal will play with the object. This play behavior provides the opportunity to develop skills and strategies with this object (i.e., tool use). It can therefore become an important part of an animal development and adaptation (Vandenberg 1978).

Focusing on the development of human social cognition, Tomasello's theory describes not only the sequence as described above but also explains in more detail how and why children progress in their engagement with objects and materials during their early development. According to Tomasello (1999), human social cognition develops through cumulative cultural evolution. Culture is not only the human social environment and the context for cognitive 
development (i.e., cognitive habitus), but it is also the source of active instruction, through which specific knowledge gets passed on to children. Active and explicit instruction is specific to humans and ensures the cumulative effect of our cultural evolution.

An important part of this cumulative cultural evolution is learning the use of cultural tools, objects, and artifacts. Tomasello (1999) presumes that children begin to understand the concept of objects around 4 months of age. Then, at 6 months, dyadic (child and object) imperative (i.e., inquisitive or explorative) interactions between the child and an object start to emerge. During this period, children learn about the sensorimotor affordances of objects by means of exploration as referred to by Pellegrini (2013). Through joint attention behaviors (e.g., gaze following and social referencing), these interactions turn into triadic (child, object, and other person) and declarative (i.e., expressive to inform or direct the other person) interactions when the child is around 8 or 9 months of age: the 9-month revolution (Tomasello 1999; Tomasello 2019). Before 9 months, others are seen simply as beings, whereas after 9 months, children start to understand others as intentional beings like themselves (others operate "like me"), by seeing how others interact with objects.

The 9-month revolution is uniquely human, as this change in perspective combined with the unique human ability of emotion sharing creates joint intentionality (Tomasello 2019). In this latter period, the child learns about the intentional affordances of objects; this is what we (as a culture) use this (as an object/tool/artifact) for. These intentional affordances allow for and are a prerequisite to children's symbolic play: a more mature form of play. During symbolic play, the intentional affordances of a particular object are endowed upon another object (e.g., a stick can be used as a spoon).

Children learn about these intentional affordances through stimulus enhancement, emulation learning, and imitative learning (Pellegrini 2013; Tomasello 1999; Tomasello 2019). The first mechanism to emerge, stimulus enhancement, happens when other intentional beings (e.g., adults/parents) use an object and by doing so, facilitate a child's interest in the object. Secondly, emulation learning refers to when a child (often before the age of one) discovers new (additional) affordances of an object because they see another intentional being using that object. The focus of emulation learning lies on the affordance discovered or outcome of the action rather than the exact action(s) of the intentional being. Lastly, often after the age of 1 year, imitative learning occurs when a child directly copies what they see other intentional beings do with an object to create the same result.

One of the main differences between emulation and imitative learning is that emulation learning focuses on reaching the same outcome via whichever means necessary, where imitation learning focuses on reaching the same outcome by imitating the exact action(s). When comparing across species, it has been found that chimpanzees, for example, engage more often in emulation learning, focusing on obtaining the same outcome. Children, on the other hand, are more interested in all actions involved to reach this outcome and tend to (over)-imitate their surroundings (Horner and Whiten 2005; Nielsen 2012).

Another comparison between these two species shows that, due to the cumulative cultural evolution of humans, emulation and imitation learning have migrated to an earlier stage of human ontogeny. For humans, these behaviors appear around 1 year of age, where chimpanzees engage in these behaviors around 3 years of age (Tomasello 2019). With respect to children's exploration and/or manipulation of objects and materials, all three mechanisms present themselves during child-caregiver joint attention and stimulate a child's progression through the developmental trajectory of this behavioral phenomenon. 


\section{The Developmental Value of Children's Exploration and/or Manipulation of Objects and Materials}

\section{Adaptation}

Interestingly, object interaction is not only present in humans but also in most mammalian species. These species spent a significant percentage of time and energy engaging in exploration, object play, and tool use (Pellegrini \& Bjorklund, 2004). Considering their costs (time and energy), these behaviors should be functional: the benefits outweigh the costs. Therefore, the exploration and/or manipulation of objects and materials must be of some evolutionary value (Power 2000). So, what might be the evolutionary value of object interaction? Some of the suggested evolutionary benefits are the acquisition of information regarding the rules of objects in one's surrounding, the practice of motor skills, the occurrence of novel behavioral sequences that can result in new forms of tool use (see section on tool use below), and possibly the stimulation of cognitive development (Power 2000).

For the human species specifically, the manipulation and exploration of objects and materials is assumed to have both ontogenetic and deferred adaptive value: It supports the adaptation to the immediate and future environment (Pellegrini et al. 2007; Smith and Pellegrini 2008). Not only is immediate cardiovascular conditioning supported by object interactions, such as mouthing, dropping, assembling, or otherwise manipulating objects, but these interactions also allow for children to try out new combinations of actions free of external constraint. Therefore, it supports them in gaining knowledge about the (cultural use of) objects and their surroundings (Smith and Pellegrini 2008; Pellegrini 2013).

Based on this knowledge, children can develop new strategies and behaviors that can influence evolutionary processes. In other words, these new strategies and behaviors create phenotypic variation: the fundamental principle of evolution by natural selection (Bjorklund 2012; Pellegrini et al. 2007). If the phenotypic variation created through these interactions with objects would not support the adaptation of our species, these interactions would have been eliminated by natural selection considering their costs (Bjorklund and Gardiner 2011; Ellis 1973; Riede et al. 2018).

\section{Tool Use}

Through exploring objects and materials in their surroundings during the first years of their life, children learn about the use and function of tools. This phase of exploration can be viewed as consisting of perception-action routines through which children gather information, for example by trying to relate objects to other objects or surfaces in their surroundings (Lockman 2000). However, children not only learn about the instrumental function of tools. Because of their tendency to (over)-imitate their surroundings, they also learn about the cultural function of the tools and the associated cultural normative behavior (Legare and Nielsen 2015). The tendency of children to over-imitate and, as a consequence, use these objects only as tools for their intended function, is thought to be distinctive to human intelligence and results in efficient long-term tool use (Casler and Kellemen 2005).

\section{Social Cognition}

The emergence of joint attention behaviors, where the child and another person are jointly engaged with an object, signifies what Tomasello (1999) calls the 9-month revolution. This 
represents the beginning of the development of human social cognition (Tomasello 1999). After learning about the sensorimotor affordances of objects, children discover a new dimension of objects: the "ideal" dimension where the child learns about the intentional affordances of objects. Therefore, the interactions with objects (e.g., exploration, object play, or tool use) that take place during joint attention, drive and support the development of social cognition.

\section{Concluding Remarks}

Our discussion of the evolutionary psychology perspective shows how the exploration and/or manipulation of objects and materials is to be understood when comparing human behavior to similar behaviors in different species. This cross-species comparison underscores the important role of our interactions with objects and materials, not only in the development of a child but for us humans as a species. See Table 1 for an overview of the main concepts and ideas of this perspective.

\section{Comparison of the Three Perspectives and Synthesis of Answers}

In this section, we will discuss and compare the similarities and differences between the three theoretical perspectives on the exploration and/or manipulation of objects and materials in order to integrate them into comprehensive answers to the questions posed in the introduction: Q1. What are the defining labels and features of the exploration and/or manipulation of objects and materials by children in early childhood?; Q2. What is the developmental trajectory of the exploration and/or manipulation of objects and materials by children in early childhood?; Q3. What is the developmental value of the exploration and/or manipulation of objects and materials by children in early childhood?

To answer these questions, we will look for recurring ideas and themes, as well as whether these ideas are backed up by other (more recent) empirical research or literature reviews. By discussing the three perspectives side by side, it will also become apparent where the perspectives complement each other. In each subsection, we will start with the discussion and comparison of the three perspectives and then we will conclude with our integration of these perspectives into an answer to our research questions. Ultimately, the answers to our questions will lead to a theoretical framework, which can support childhood educators and can also be used as a foundation to inform future research on the exploration and/or manipulation of objects and materials in early childhood education.

\section{The Three Perspectives on the Defining Labels and Features of the Exploration and/ or Manipulation of Objects and Materials by Children in Early Childhood}

The first aspect that becomes apparent when comparing the different perspectives is that despite the many different labels (e.g., practice play, manipulative play, tool use, or object play), all three perspectives emphasize learning as an important feature of a child's exploration and/or manipulation of objects and materials. Where the genetic epistemology perspective specifically emphasizes the habituation of existing behaviors through the repetition that is typical during practice play, the evolutionary psychology perspective specifically emphasizes the importance of learning to use cultural tools or objects to ensure our human cumulative cultural evolution (Piaget 1967/1951; Tomasello 1999). Moreover, the cultural historical 
psychology perspective highlights learning, defined as optimizing current actions or learning new actions, as the intrinsic function of any activity, including a child's exploration or manipulation of objects (Van Oers 2010).

When integrating the three perspectives with respect to the defining features of the exploration and/or manipulation of objects and materials, it becomes apparent that our theoretical framework needs to underscore that learning is inherently related to this behavior. To highlight the importance of learning in relation to (object-oriented) play, Van Oers' ideas on play from a cultural historical psychology perspective might be helpful. Van Oers (2010) has inherently linked play to learning, by defining it as a play format: a mode of engaging in any cultural activity, that is characterized by high involvement, following implicit or explicit rules, and degrees of freedom. In this context, learning is understood to be either a qualitative change in behavior or habituating existing behaviors. This habituation, in turn, creates new possibilities for new or more complex behavior to develop, through association or the emergence of new needs (Van Oers 2010). In other words, play is defined as a mode of engaging in an activity instead of a separate activity with its own separate label. If the three aforementioned characteristics are absent, the activity would likely be regarded as chaotic (i.e., to many degrees of freedom), forced (i.e., to many rules that has to be followed), or uninteresting to the child (i.e., no high involvement or involuntary participation). However, if these characteristics are present, the child's engagement in the exploration and/or manipulation of objects and materials provides the opportunity for learning to take place, which makes the behavior functional in a child's development.

To adequately represent our discussion of the three perspectives, one parameter needs to be further explicated to encompass all learning that can potentially take place. Van Oers' parameter of following rules is applicable to the exploration and/or manipulation of objects and materials if it not only encompasses following but also discovering rules. The discovery of rules is an important feature of children's interactions with objects within the evolutionary psychology perspective (Hutt 1966; Pellegrini 2013; Tomasello 1999).

The rules or regularities that children discover or learn about during their exploration and/or manipulation of objects and materials can be twofold. Firstly, they can learn about the sensorimotor affordances: the rules of the object or material (e.g., a sponge is soft and squishy and holds its form). Secondly, they can learn about the rules of how we, as a culture, use the object or material: the intentional affordances (e.g., a sponge is used to wipe or clean things), as described by Tomasello (1999). The discovery of rules, whether sensorimotor, intentional, or even conceptual, through exploration and manipulation has been well established by the theoretical work of Lockman (2000) on perception-action routines and has been confirmed in several empirical studies (Berger et al. 2005; Cook et al. 2011).

Interestingly, the parameters of Van Oers' (2010) play theory are very similar to Rubin et al. (1983) description of the dispositions of play: (1) being highly involved, (2) intrinsically motivated for the sake of play(ing), (3) deriving pleasure from it, and (4) having the freedom to modify the rules within the play. Although both the dispositions of "intrinsic motivation" and that of "pleasure" are not explicitly stated in Van Oers' parameters, these dispositions are inherently linked to the parameters of a high level of involvement in combination with degrees of freedom; if children have some degrees of freedom to act as they want and have a high level of involvement, their actions can become intrinsically motivated. This might result in children deriving some sort of satisfaction from it.

Van Oers' play theory has only been extensively theorized and studied in the context of more "mature" forms of play, such as pretend play. However, by comparing the three 
parameters to the dispositions identified by the extensive review of play by Rubin et al. (1983), we argue that Van Oers' explicated parameters can be considered to encompass all the behaviors of interest and provide us with the means to define the different behaviors mentioned within the three perspectives with one label: play. This label does not refer to an actual behavior, it refers to the mode of engagement: with a high level of involvement and degrees of freedom, while following or discovering rules. It should be noted that there is much theoretical discussion on what play is. For this current theoretical framework, the unifying label play as a mode of engagement is employed to link the aforementioned behaviors to learning, not to contribute to the discussion on the conceptualization of play.

Another aspect that becomes apparent when comparing the different perspectives is that the defining features of the exploration and/or manipulation of objects and materials can be divided into concrete behaviors (e.g., banging an object, relating two object to each other, or substituting an object) and characteristics of this behavior (e.g., repetition, imitation, and association). The concrete behaviors can be categorized as follows: sensorimotor exploration, physical manipulation, and mental manipulation. Although the three theoretical perspectives use different labels to refer to these behaviors, the general function of these behaviors is similar. First, the sensorimotor exploration behaviors, in the genetic epistemology perspective, are described as primary and secondary circular reactions, or what Casby (2003) termed exploratory sensorimotor play. In cultural historical psychology, it refers to behaviors that serve a child's exploratory orientation. These behaviors are simply referred to as exploration in the evolutionary psychology perspective. In all three perspectives, the general developmental function of sensorimotor exploration behaviors is discovering the sensorimotor affordances or rules of objects and materials.

The second category of behaviors, mentioned in all three perspectives, would qualify as physical manipulation. These behaviors are referred to as practice play, constructive play, nonconventional relational play, manipulative play, object play, tool use, etc., across the three perspectives. Even though all these labels refer to different behaviors, they would all qualify as physical manipulations of objects and materials with the goal of discovering what one can do with an object or material, manipulating the object according to their rules or intentional affordances (i.e., their social function), and practicing for the habituation of behaviors and social schemes. Finally, all three perspectives refer to behaviors that constitute as object substitution or some form of mental manipulation of objects and materials, for the sake of discovering the possibilities of the object(s) or material(s) when combined with symbolic thought (e.g., endowing intentional affordances of one object onto another object) and practicing these different forms of symbolic thought.

The recurrent and defining characteristics of these behaviors that are mentioned within the three perspectives, such as repetition, imitation, and association, are all mechanisms that create opportunities for learning to take place. These mechanisms occur during a child's dyadic and triadic interaction with their environment. They can therefore be summarized as different dyadic and triadic learning mechanisms that support the developmental trajectory of the exploration and/or manipulation of objects and materials and will be discussed in the section concerning the developmental trajectory.

\section{Q1: What Are the Defining Labels and Features of the Exploration and/or Manipulation of Objects and Materials by Children in Early Childhood?}

From our discussion, we can extract the following answer to the first research question. When children (1) show a high level of involvement, (2) have some degrees of freedom to explore 
and manipulate as they please, and (3) are also following and discovering rules, we can argue that they are engaged in play, which inherently means it provides an opportunity for learning. When play is focused on exploring and/or (physically/mentally) manipulating objects and materials, we will further refer to this behavioral phenomenon as object-oriented play. In the next part of this paper, we will use the term object-oriented play (abbreviated as OOP) as a new and overarching label that integrates the labels used in the three different perspectives.

In other words, OOP is all play that is focused on objects or materials and their sensorimotor or intentional affordances. This can involve the sensorimotor exploration, physical manipulation, or mental manipulation of objects and/or materials. These labels are broad behavioral categories that can include several different and more specific behaviors (see Table 2). Sensorimotor exploration refers to all behaviors involved in discovering the sensorimotor affordances and rules of objects and materials. Physical manipulation refers to manipulating and handling the objects or materials in order to discover what one can do with the object(s) or material(s), as well as manipulating them following certain rules such as their intentional affordances. Mental manipulation refers to the substitution or representation of objects and supports the child development of symbolic thought.

Having a unified label for this behavioral phenomenon, knowing when and how it can provide the most optimal opportunity for learning or development to take place, and knowing what specific behaviors it entails, can support childhood educators to identify, understand, and enrich children's OOP. Figure 1 illustrates our conceptualization of this behavioral phenomenon that results from our theoretical synthesis of OOP.

\section{The Three Perspectives on the Developmental Trajectory of the Exploration and/or Manipulation of Objects and Materials by Children in Early Childhood}

All three perspectives differ substantially regarding their overall view on the developmental trajectory of OOP. Both the genetic epistemology and cultural historical psychology perspective have their own theory regarding the mechanisms and "phases" of development. According to the genetic epistemology perspective, a child's own cognitive developmental accomplishments through imitation and repetition ensure a child's transition through several set stages. For cultural historical psychology, it is the mediation of the surroundings and a child's new leading motives that supports a child's transition from one leading activity to the next. The evolutionary psychology perspective is less clear on the developmental sequence and relation between the different behaviors. They only state that exploration precedes all other interactions with objects and that children start to understand others as intentional beings during the 9month revolution. This perspective is, however, very clear about the mechanisms involved in the developmental trajectory of OOP: stimulus enhancement, emulation, and imitation, as explained the section concerning the evolutionary psychological interpretation on the developmental trajectory.

All three perspectives do agree on the fact that OOP will eventually lead to some form of symbolic play, once a child has the cognitive ability for symbolic thought (Piaget 1967/1951; El'konin 1989; Tomasello 1999). This developmental trajectory starts with the mental manipulation of objects: symbolically changing the function, meaning, or attribute of the object, while remaining focused on that specific object. The ability to mentally manipulate objects will eventually allow for more mature forms of play to develop, such as pretend play.

Specifically, between the genetic epistemology and the cultural historical psychology perspective, there are also several significant similarities regarding their views on the 
Table 2 Overview of the developmental phases, functions, behaviors, and learning mechanisms of OOP

\begin{tabular}{|c|c|c|c|}
\hline $\begin{array}{l}\text { Developmental } \\
\text { phases } \rightarrow>\end{array}$ & Sensorimotor exploration & Physical manipulation & Mental manipulation \\
\hline Function(s) & $\begin{array}{l}\text { 1. Discovering the } \\
\text { sensorimotor affordances } \\
\text { and the } \\
\text { (physical/technical) rules } \\
\text { of the object(s) or } \\
\text { material(s) }\end{array}$ & $\begin{array}{l}\text { 1. Practicing for the habituation of } \\
\text { behaviors and social schemes } \\
\text { 2. Discovering what one can do } \\
\text { with the object(s) or } \\
\text { material(s) and their } \\
\text { sensorimotor affordances } \\
\text { 3. Discovering what one can do } \\
\text { with the object(s) or } \\
\text { material(s) and their intentional } \\
\text { affordances } \\
\text { 4. Discovering and following } \\
\text { (social, technical, and } \\
\text { sometimes strategic and } \\
\text { conceptual) rules }\end{array}$ & $\begin{array}{l}\text { 1. Discovering and } \\
\text { following (social, } \\
\text { strategic, and } \\
\text { conceptual) rules } \\
\text { 2. Discovering the } \\
\text { possibilities of the } \\
\text { object(s) or material(s) } \\
\text { when combined with } \\
\text { symbolic thought } \\
\text { 3. Practicing different } \\
\text { forms of symbolic } \\
\text { thought }\end{array}$ \\
\hline Behaviors & $\begin{array}{l}\text { - Mouthing, } \\
\text { - Squeezing, } \\
\text { - Banging, } \\
\text { - Stroking, } \\
\text { - Kneading, } \\
\text { - Rotating, } \\
\text { - Inspecting objects and } \\
\text { materials }\end{array}$ & $\begin{array}{l}\text { One object: } \\
\text { - Repeating a manipulation with } \\
\text { an object or material } \\
\text { (nonfunctional) } \\
\text { - Using an object in a new or } \\
\text { unconventional way (creative) } \\
\text { - Using an object in service of a } \\
\text { goal (tool use) } \\
\text { Multiple objects (relational) } \\
\text { - Nonfunctional combining of } \\
\text { objects } \\
\text { - } \\
\text { Sorting/grouping/stacking/- } \\
\text { nesting } \\
\text { - Nonconventional combining of } \\
\text { objects (creative) } \\
\text { - Creating patterns } \\
\text { - Counting objects } \\
\text { - Combining objects according to } \\
\text { cultural function }\end{array}$ & $\begin{array}{l}\text { - Substituting objects } \\
\text { - Representation of objects: } \\
\text { the "manipulation" of } \\
\text { objects that are not } \\
\text { physically present }\end{array}$ \\
\hline $\begin{array}{l}\text { Learning } \\
\text { mechanisms }\end{array}$ & $\begin{array}{l}\text { - Repetition (dyadic) } \\
\text { - Association (dyadic) } \\
\text { - Stimulus enhancement } \\
\quad \text { (triadic) }\end{array}$ & $\begin{array}{l}\text { - Repetition (dyadic) } \\
\text { - Association (dyadic) } \\
\text { - Emulation (triadic) } \\
\text { - Imitation (triadic) }\end{array}$ & $\begin{array}{l}\text { - Repetition (dyadic) } \\
\text { - Association (dyadic) } \\
\text { - Imitation (triadic) }\end{array}$ \\
\hline
\end{tabular}

developmental trajectory of OOP. In order to grasp these similarities, we need to take a closer look at the sequence of the developmental trajectory. Both the genetic epistemological interpretation of practice play accompanying the sensorimotor stage and the cultural historical psychology interpretation of manipulative play as a leading activity view OOP as an important (first) step within the cognitive development of children (El'konin 1971; Piaget 1970; Vygotsky 1933/1967). Within both perspectives, it occurs around the same age (somewhere between 4 and 12 months) and is focused on sensorimotor skill development and exploring the physical surroundings. According to the genetic epistemology perspective, this is a result of a child's interaction with the (material) surroundings, for the cultural historical psychology perspective, it is a result of a child's social interaction with their surroundings (e.g., caregivers). 


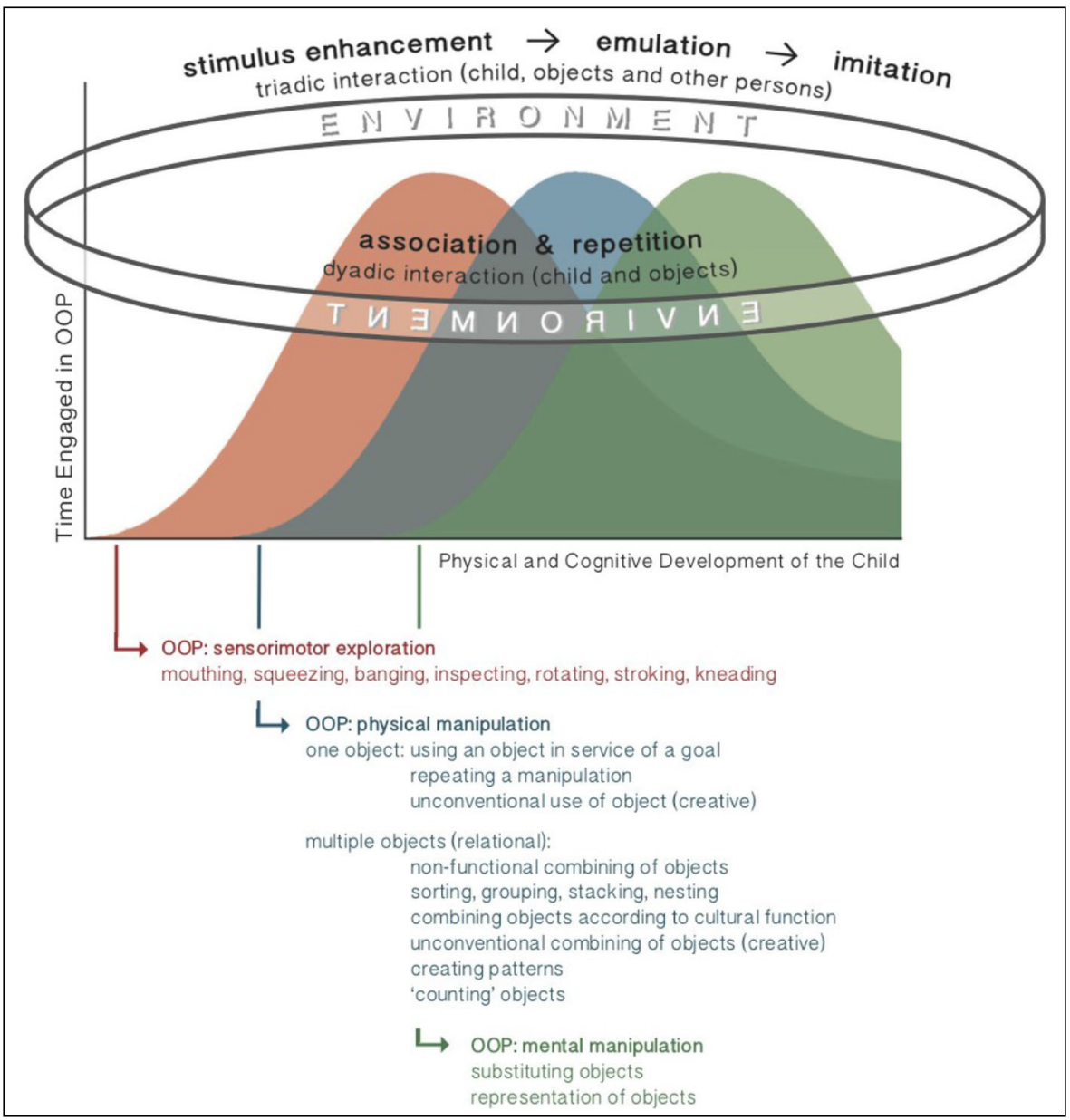

Fig. 1 Theoretical framework of object-oriented play (OOP). Note. Object-oriented play (OOP) is play focused on exploring and/or manipulating objects and materials, both physically and mentally. During OOP, a child is (1) highly involved, (2) has some degrees of freedom, and (3) follows and/or discovers rules. This provides opportunities for learning and is of evolutionary, cultural, and cognitive value. The developmental trajectory of OOP can best be represented as overlapping waves of increasingly complex behaviors (i.e., sensorimotor exploration, physical manipulation, and mental manipulation). The learning mechanisms (i.e., association, repetition, stimulus enhancement, emulation, and imitation) that occur during a child's dyadic and triadic interactions with their environment promote this developmental trajectory of OOP

Both perspectives propose a hierarchical trajectory of OOP, although they differ in the steps they distinguish within this trajectory. The cultural historical psychology perspective distinguishes two types of manipulative thought: (1) explorations (and manipulations) during the first year of life, to learn about the characteristics of the object, which serves the child's exploratory orientation within reality (Gal'perin 1980) and (2) the manipulation of objects during the second and third year of life, to attain a practical goal and the manipulation of objects according to their social meanings, which serves as the child's orientation on a cultural activity (Gal'perin 1980). Within the genetic epistemology perspective, Piaget (1967/1951)) subdivided the sensorimotor stage into the different circular reactions and based upon this, Casby (2003) created a hierarchical sequence of exploratory sensorimotor play, relational- 
nonfunctional play, and functional-conventional play, stretching from around 4 months till 18 months. This hierarchical sequence is also in line with the view of the evolutionary psychology perspective, in which the interactions with objects start with (sensorimotor) exploration, around $8-10$ months.

It is also interesting to note that both cultural historical psychology and evolutionary psychology mention that when a child is around 1 year old, their attention turns from dyadic to triadic interactions, indicating that children develop the capacity to direct their attention to multiple things (e.g., caregivers and objects) at the same time, as well as that they learn to direct others' attention. This development follows the 9-month revolution as explained by Tomasello (1999).

The proposed hierarchical sequence of the phases of OOP, as well as the more specific and concrete behaviors these phases entail, has also been confirmed by empirical research such as the studies by Belsky and Most (1981) and Tamis-LeMonda and Bornstein (1994). Belsky and Most (1981) hypothesized a developmental sequence of exploration to play based on a crosssectional study of free play. This developmental sequence starts around 7.5 months with undifferentiated exploration, develops into increasingly complex forms of manipulations, and eventually leads to decontextualized (symbolic) play. A similar sequence, from simple to gradually more complex manipulations leading to a transition into symbolic play, is used in a study by Tamis-LeMonda and Bornstein (1994) to indicate the level of symbolic play in relation to different aspects of children's language. Both these studies suggest that several steps exist within the manipulatory phase of play and that there is a transitional phase towards more symbolic play. These studies provide an example of the empirical work that has already been done to support the hierarchical phases and sequence of behaviors, as hypothesized by the discussed perspectives.

On an abstract level, there is a second similarity between the genetic epistemology and cultural historical psychology perspective. Their founders Piaget and Vygotsky viewed development as advancing in one direction towards a specific goal, which to Piaget was scientific logic and for Vygotsky becoming a member of one's own culture (Matusov and Hayes 2000). Because Piaget (1967/1951) saw development as a one directional progression, always from simple to more complex, through a set sequence of stages, he failed to recognize the possibilities of a child going back and forth between sensorimotor and "higher" cognitive processes for example. Smilansky (1968) nuanced Piaget's (1967/1951) view on stages by admitting that stages at some point can exist parallel to one another, as a child gradually moves from one stage to the next within the set sequence. Similarly to Smilansky, the theorists succeeding Vygotsky also argued that each age period is characterized by a leading activity (indicating the way children relate to their surroundings), which at that point in a child's development is the most prominent activity. This does not mean that another activity is excluded; it is just more prominent at that time (Van Oers 2011). Ultimately, both perspectives adopted a more flexible view on the progression of development.

More recent studies used the overlapping waves theory, developed by Siegler in 1996, to corroborate the idea that multiple behaviors, indicative of a stage or leading activity, can be present at the same time (Forestier and Oudeyer 2016a, 2016b). In their study on the role of tool use in the development of human cognition, Forestier and Oudeyer (2016b) showed that overlapping waves of qualitatively different types of behaviors can be useful for children to discover sensorimotor knowledge and solve sensorimotor problems. This indicates that multiple behaviors or strategies can be present at the same time, and that children do not always use the most optimal, complex, or newly acquired behavior. Using less optimal behaviors or 
strategies can help children scaffold their own understanding of the increasingly complex affordances within their environment (Forestier and Oudeyer 2016a). This view allows for more flexibility in the sequence and occurrence of behaviors across time and is more in line with the often associative nature of OOP.

A final abstract similarity between the two perspectives is that one could argue that both the genetic epistemology and cultural historical psychology perspective do not sufficiently highlight the importance of the interaction between a child's own cognitive development and the social context (Matusov and Hayes 2000). Where the genetic epistemology perspective mainly focuses on the child's own cognitive development, the cultural historical psychology perspective mainly focuses on the social context.

According to the genetic epistemological perspective, the role of an adult is to facilitate the physical environment and to observe the child (Beckett et al. 2017; Matusov and Hayes 2000). This marginal role of the adult does not take into consideration the possible influence of adult(s) as social beings in the child's environment as well as the possible interactions with these adult(s) that could impact the child's play or development (Beckett et al. 2017). Both Piaget (1962) and Smilansky (1968) did, however, mention imitation as a possible influence from the environment. The evolutionary psychology and the cultural historical psychology perspective (Pellegrini 2009; Vygotsky 1933/1967) are more explicit on the role of imitation: Both perspectives consider it to be a crucial mechanism for (play) development.

In the cultural historical psychology perspective, the role of mediation by the social context and environment in a child's development has a prominent place. According to El'Konin (1971) and Leont'ev (1972/1981), mediation of the environment ensures the transition into a new leading activity that accompanies each age period. One could argue that this perspective, in turn, gives too little attention to the influence of the child's own actions and maturation in this transition to new leading activities. Many scholars have criticized Vygotsky for placing too much focus on the influence of the cultural context. However, as Van Oers (2011) points out, Vygotsky himself actually did emphasize that children's own activity is the basis for their development.

By synthesizing the ideas of genetic epistemology and cultural historical psychology into a unified framework, it becomes possible to highlight the importance of both a child's own cognitive development as well as their social context in play activities. This also permits the consideration of the interaction between a child's own cognitive development and their social context, which is necessary for a comprehensive view on the developmental trajectory of OOP. In other words, a child's development never occurs in isolation from the social context. This view is also in line with a more recent sociocultural perspective on development, where the cognitive development of children is regarded as inherently embedded within the social context (Matusov and Hayes 2000). This is especially important to consider within an (early) childhood education context.

Many similarities, as well as complementing factors, can also be found across all three perspectives when considering the different mechanisms (the defining features as described earlier) important to the developmental trajectory of OOP. Even though these mechanisms may differ substantially between the different perspectives on a behavioral level, on a functional level, there are some interesting similarities to consider. They are all learning mechanisms that support the development of children's OOP and occur during a child's dyadic (child and objects) or triadic (child, objects, and other persons) interaction with their environment. The recurrence of some of these learning mechanisms across the different 
perspectives could be an indication of their importance to the developmental trajectory of OOP.

During a child's dyadic interactions with their environment (child and objects), two learning mechanisms important to the development of children's OOP occur: repetition and association. Repetition, a concept mentioned in the genetic epistemology, is of importance for the habituation of actions and behaviors. Association, a concept mentioned in the cultural historical perspective, can support the development of qualitatively new behaviors. The learning (i.e., the habituation of actions and behaviors and the development of qualitatively new behaviors) that takes place, in turn, supports the developmental progression of children's OOP.

During a child's triadic interactions with their environment, three learning mechanisms can be distinguished: (1) stimulus enhancement, (2) emulation learning, and (3) imitation. These three mechanisms can all be seen as a type of mediation during child-caregiver joint attention, a key concept within cultural historical psychology. Both the cultural historical psychology perspective and the evolutionary psychology perspective agree that the interaction of adults with objects can stimulate the interest of a child to explore or manipulate a certain object. The evolutionary psychology perspective specifically coined the term stimulus enhancement to refer to this mechanism. Emulation learning is considered an important mechanism before the age of one, in the evolutionary psychology and cultural historical psychology perspective and occurs when someone in a child's surroundings is using or handling a certain object. Imitation is a mechanism that is recurrent within all three theoretical perspectives and develops after the age of one (Tomasello 1999). The prominent presence of imitation across all three perspectives not only demonstrates the importance of this mechanism but also underpins the importance of the child's surroundings, as children need their surroundings (i.e., caregivers, teachers, or more knowledgeable others) to imitate when exploring or manipulating objects. These three learning mechanisms underscore the importance of a child's triadic interactions with their environment to the development of OOP.

\section{Q2. What Is the Developmental Trajectory of the Exploration and/or Manipulation of Objects and Materials by Children in Early Childhood?}

Based on our discussion of the ideas brought forth within the three discussed perspectives, we can conclude that OOP develops in certain developmental phases, often from simple behaviors and interactions to more complex. In general, OOP starts with sensorimotor exploration, as a child first needs to know the objects' sensorimotor affordances before they can intentionally manipulate the object. After this first developmental phase, a child moves to more complex physical manipulation of objects and materials. Finally, once a child develops the cognitive ability for symbolic thought, physical manipulation can develop into mental manipulation of objects and material. Mental manipulation can be viewed as an initiation of more mature forms of play such as pretend play, where the objects become props within the narrative of children's play (Thompson and Goldstein 2019). These broader labels (sensorimotor exploration, physical manipulation, and mental manipulation) for the developmental phases within OOP exist out of many different more specific and concrete behaviors, which are described in more detail in Table 2.

It is important to note that the developmental trajectory of OOP consist out of hierarchical behavioral phases that are cumulative, not mutually exclusive. Multiple behaviors, both simple and complex, can be present and utilized at the same time, as the cognition of a child grows 
and changes during the course of their development. For example, children can switch back and forth between exploring and manipulating an object as they discover new affordances during the activity. This can best be seen as overlapping waves of developmental phases as represented in Fig. 1. There is a hierarchical sequence in the occurrence of the behavioral phases. Even though each phase has their peak at a different time (between the ages of approximately 18 months until 3.5 years), all encompassed behaviors can be present in the behavioral repertoire of a child at the same time.

The progression through the developmental trajectory of OOP is both influenced by the child's own physical and cognitive development as well as the social context, as these two constantly interact with each other. Altogether, a child's physical and cognitive development - and other dyadic learning mechanisms, such as repetition and association - in combination with mediation by their surroundings - through triadic learning mechanisms, such as stimulus enhancement, emulation, and imitation-lead to overlapping waves of behavior: starting with sensorimotor exploration, then physical manipulation and lastly mental manipulation. These insights can support childhood educators to navigate the progression of children's OOP as well as understand the mechanisms that promote this progression. Figure 1 portrays the developmental trajectory within our comprehensive view of OOP.

\section{The Three Perspectives on the Developmental Value of the Exploration and/or Manipulation of Objects and Materials by Children in Early Childhood}

Across all three perspectives, OOP is linked to children's learning and development in several domains such as the development of cognitive schemes, language learning, symbolic thought, social cognition, sensorimotor knowledge and skills, and even human adaptation. The developmental value of OOP has also been assessed and confirmed by many empirical studies (e.g., Forestier and Oudeyer 2016b; Wyman et al. 2009; Pellegrini and Gustafson 2005).

In all three perspectives, OOP is consistently linked to children's cognitive development, specifically the development of children's schemes, language, and symbolic thought. Schemes, a concept used in genetic epistemology, refer to a cognitive structure that helps a child to interpret and organize information. This relates to the procedure of a psychological tool as used in cultural historical psychology. Both perspectives view schemes and psychological tools as cognitive structures that support a child's cognitive development. These cognitive structures are still considered of great importance to children's development, as they can support children to construct their understanding of the world around them (Atherton and Nutbrown 2013; Arnold 2013; Athey 2013).

Both the cultural historical psychology and evolutionary psychology perspectives link the start of language development to OOP. OOP has the potential to influence the language development of a child, because they often learn the name and defining characteristics of the object they are interacting with (Vygotsky 1933/1967). This focus on objects also provides opportunities for children to develop their functional vocabulary (Van Oers 2010). Within the evolutionary psychology perspective, Tomasello (2003) argued that the joint attention during OOP is crucial for language development. OOP provides a pragmatically simple situation in which the communicative intention of the caregiver or teacher is especially clear to a child. It therefore helps the child in their acquisition of concrete nouns and perceptible referents (Tomasello 2003).

A large body of empirical research confirmed the relation between OOP and children's language. Several studies show that OOP contributes to children's word learning or show that 
OOP functions as a context for mothers to provide didactic language to their children (TamisLeMonda et al. 2013; Yu and Smith 2012). More specifically, some recent studies looked into the relations between object exploration while sitting or walking and the development of spatial language (Oudgenoeg-Paz et al. 2015; Oudgenoeg-Paz et al. 2016). These studies found that children's independent sitting and walking enables more object exploration, which in turn supports children to learn about spatial concepts and contributes to the acquisition of spatial language (see also Halliday 2006).

The development of symbolic thought is also thought to be stimulated by OOP. In all three perspectives, the mental manipulation of objects, such as substitution, is considered as a transition phase to other (more mature) forms of play such as pretend play. The exhaustive review on pretend play by Thompson and Goldstein (2019a, b) confirmed that object substitution is indeed viewed as the first component of the developmental progression of pretend play.

Next to children's cognitive development, OOP might also support the development of children's social cognition. Both the cultural historical psychology and the evolutionary psychology perspective link OOP to the start of the development of children's social cognition. Van Oers (2010), for example, argued that the development of social-emotional stability is rooted in children's manipulative play. Within the evolutionary psychology perspective, interactions with objects (e.g., tool use) are considered as paramount to our adaptation and the survival of our species as social humans, with cumulative cultural evolution as an important mechanism (Tomasello 1999). More recent studies also found that OOP facilitates social communication before children have developed their verbal language skills (Kultti and Pramling 2015).

Even though all three perspectives agree that children's gross and fine motor skills are a prerequisite for OOP, the only perspective that describes the contribution of OOP to the development of children's motor skills is genetic epistemology. Within the sensorimotor stage, Piaget (1967/1951) distinguished the different motor developments (e.g., circular reactions) of children that allow for new possibilities of exploration and/or manipulation. Many recent studies confirmed that the development of motor skills provides new possibilities in a child's development (Karasik et al. 2011; Libertus et al. 2015; Soska and Adolph 2014). A child that can grasp, can start exploring, a child that has more refined motor skills, can start to manipulate objects in more detail, and a child that can walk, has many more objects and materials at their disposal. Smilansky (1968) also pointed out that repetition during functional play contributes to children's motor development, as it includes the repetition of simple muscular activities. It is, therefore, very important to also take a child's motor development into account when assessing the developmental value of OOP.

The three perspectives have also linked OOP to more immediate functions. All perspectives view OOP as a context in which children can discover the sensorimotor affordances of objects and materials, and practice for the habituation of behaviors, social schemes, and different forms of symbolic thought. The cultural historical psychology and evolutionary psychology also relate OOP to a child's discovery of the intentional affordances of objects. Lastly, the cultural historical psychology perspective mentions the opportunity OOP provides to discover and follow different rules (i.e., physical, technical, social, conceptual, and strategic rules).

\section{Q3. What Is the Developmental Value of the Exploration and/or Manipulation of Objects and/or Materials by Children Ages of 1.5 to 5 Years Old?}

Overall, the three theoretical perspectives agree that OOP is of great developmental value to children, which might explain the universality and pervasiveness of this behavior across time, 
cultures, and species (Göncü et al. 2000; Power 2000; Riede et al. 2018). Each perspective provides arguments regarding the developmental value of OOP for many different areas of development: cognitive development (e.g., language learning, schemes, and symbolic thought), social cognition (e.g., influencing our evolutionary adaptation through cultural tool use), and (sensori)motor development. Apart from potentially supporting different developmental domains, OOP can provide a context for children to discover and follow rules and affordances as well as to practice acquired behaviors and schemes.

In order to support the claims made by the three perspectives and to describe the developmental value in more detail, future research should focus on conducting a systematic review or meta-analysis of empirical studies on the developmental value of OOP, for example concerning the relationship between OOP and children's cognitive development. Gaining more knowledge on the relationship between OOP and cognitive development can help childhood educators to accurately enrich children's OOP and support their development.

\section{Conclusion}

After reviewing three theoretical perspectives-genetic epistemology, cultural historical psychology, and evolutionary psychology-concerning their view on children's exploration and/or manipulation of objects and materials, it has become evident there are many similarities between them and that the differences between the perspectives can complement each other. By discussing and comparing these perspectives, we have synthesized a unified theoretical framework that can support childhood educators in understanding, supporting, and enriching the universal and pervasive behavior that we have termed object-oriented play (OOP). In Fig. 1, we present a comprehensive theoretical framework of OOP, including the labels and defining features of the behaviors, its developmental trajectory, and developmental value. This theoretical framework can also be used to inform future research concerning the role, developmental trajectory, and developmental value of OOP in early childhood education. One specific application might be the development and validation of an observational instrument that can be used both to advance future studies on OOP and to provide further support for childhood educators to observe and assess children's OOP. It is our hope that our framework of OOP will advance the current understanding, assessment, and guidance of the behavioral phenomenon that Bobby, as one of many children, is engaged in.

Acknowledgements We would like to acknowledge Prof. Bert van Oers, Dr. Barbara Williams, Nicolette van Halem, MSc., and Tessa Slim, MSc., for their valuable feedback on earlier versions of this manuscript.

Code Availability Not applicable

Author Contribution All authors contributed to the study conception and design. The first draft of the manuscript was written by Elizabeth R. Wynberg and all authors commented on previous versions of the manuscript. All authors read and approved the final manuscript.

Funding Stichting tot Steun bij Opleiding en Begeleiding van Leerkrachten in het Christelijk Basisonderwijs \& Stichting Katholieke Opleidingsinstituten voor Onderwijsgevenden Amsterdam e.o. 
Data Availability Not applicable

\section{Declarations}

\section{Competing Interests Not applicable}

Open Access This article is licensed under a Creative Commons Attribution 4.0 International License, which permits use, sharing, adaptation, distribution and reproduction in any medium or format, as long as you give appropriate credit to the original author(s) and the source, provide a link to the Creative Commons licence, and indicate if changes were made. The images or other third party material in this article are included in the article's Creative Commons licence, unless indicated otherwise in a credit line to the material. If material is not included in the article's Creative Commons licence and your intended use is not permitted by statutory regulation or exceeds the permitted use, you will need to obtain permission directly from the copyright holder. To view a copy of this licence, visit http://creativecommons.org/licenses/by/4.0/.

\section{References}

Arnold, C. (2013). Drawing our learning together from the case studies. In K. Mairs \& C. Arnold (Eds.), Young children learning through schemas: Deepening the dialogue about learning in the home and in the nursery (pp. 169-174). London, UK: Routledge.

Atherton, F., \& Nutbrown, C. (2013). Understanding schemas and young children: From birth to three. London, UK: Sage.

Athey, I. (1984). Contributions of play to development. In T. D. Yawkey \& A. D. Pellegrini (Eds.), Child's play: Developmental and applied (pp. 9-27). Hillsdale, NJ: Erlbaum.

Athey, C. (2013). Beginning with the theory about schemas. In K. Mairs \& C. Arnold (Eds.), Young children learning through schemas: Deepening the dialogue about learning in the home and in the nursery (pp. 516). London, UK: Routledge.

Beckett, C. À., Lynch, S., \& Pike, D. (2017). Playing with theory. In S. Lynch, D. Pike, \& C. À. Beckett (Eds.), Multidisciplinary perspectives on play from birth and beyond (Vol. 18, pp. 1-22). Singapore: Springer.

Belsky, J., \& Most, R. K. (1981). From exploration to play: a cross-sectional study of infant free play behavior. Developmental Psychology, 17(5), 630-639. https://doi.org/10.1037/0012-1649.17.5.630.

Berger, S., Adolph, K., \& Lobo, S. (2005). Out of the toolbox: Toddlers differentiate wobbly and wooden handrails. Child Development, 76(6), 1294-1307. https://doi.org/10.1111/j.1467-8624.2005.00851.x.

Berlyne, D. E. (1960). Conflict, arousal and curiosity. New York, NY: McGraw-Hill.

Bjorklund, D. F. (2012). Children's thinking cognitive development and individual differences. Wadsworth, CA.: Cengage Learning.

Bjorklund, D. F., \& Gardiner, A. K. (2011). Object play and tool use: Developmental and evolutionary perspectives. In A. D. Pellegrini (Ed.), Oxford library of psychology. The Oxford handbook of the development of play (pp. 153-171). Oxford, UK: Oxford University Press.

Bjorklund, D. F., \& Pellegrini, A. D. (2002). The origins of human nature: Evolutionary developmental psychology. Washington, DC: American Psychological Association.

Bodrova, E., \& Leong, D. J. (2006). Tools of the mind. Upper Saddle River, NJ: Pearson Australia Pty Limited.

Brainerd, C. J. (1978). Piaget's theory of intelligence. Englewood Cliffs, NJ: Prentice-Hall.

Byrnes, J. P. (2008). Piaget's cognitive-developmental theory. In M. M. Haith \& J. B. Benson (Eds.), Encyclopedia of infant and early childhood development (pp. 543-552). Cambridge, MA: Academic Press.

Casby, M. W. (2003). The development of play in infants, toddlers, and young children. Communication Disorders Quarterly, 24(4), 163-174. https://doi.org/10.1177/15257401030240040201.

Case, R. (1985). Intellectual development: Birth to adulthood. New York, NY: Academic Press.

Casler, K., \& Kellemen, D. (2005). Young children's rapid learning about artifacts. Developmental Science, 8(6), 472-480. https://doi.org/10.1111/j.1467-7687.2005.00438.x.

Cook, C., Goodman, N. D., \& Schulz, L. E. (2011). Where science starts: Spontaneous experiments in preschoolers' exploratory play. Cognition, 120(3), 341-349. https://doi.org/10.1016/j.cognition.2011.03. 003 .

Demetriou, A., Spanoudis, G., \& Mouyi, A. (2011). Educating the developing mind: Towards an overarching paradigm. Educational Psychology Review, 23(4), 601-663. https://doi.org/10.1007/s10648-011-9178-3. 
Driver, R. (1978). When is a stage not a stage? A critique of Piaget's theory of cognitive development and its application to science education. Educational Research 21(1), 54-61.

El'konin, D. B. (1971). Toward the problem of stages in the mental development of children. Voprosy Psikhologii, 4, 6-20 Retrieved from https:/www.marxists.org/archive/elkonin/works/1971/stages.htm.

El'konin, D. B. (1978). Psikhologiya igry [Psychology of play]. Moscow, Russia: Pedagogika.

El'konin, D. B. (1989). Izbrannye psikhologicheskie trudy [Selected psychological works]. Moscow, Russia: Pedagogika.

Ellis, M. J. (1973). Why people play? New York, NY: Prentice-Hall.

Fischer, K. W. (1980). A theory of cognitive development: The control and construction of hierarchies of skills. Psychological Review, 87(6), 477-531. Retrieved from https://www.gse.harvard.edu/ ddl/articlesCopy/ FischerTheoryCognDev1980_old.pdf.

Fleer, M., \& Veresov, N. (2018). Cultural-historical and activity theories informing early childhood education. In M. Fleer \& B. Van Oers (Eds.), International handbook of early childhood education (pp. 47-76). Dordrecht, The Netherlands: Springer.

Forestier, S., \& Oudeyer, P.-Y. (2016a). Curiosity-driven development of tool use precursors: A computational model. 38th Annual Conference of the Cognitive Science Society (CogSci 2016), Philadelphia, PA, 18591864. Retrieved from https://hal.archives-ouvertes.fr/hal-01354013/file/paper0325.pdf

Forestier, S., \& Oudeyer, P.-Y. (2016b). Overlapping waves in tool use development: A curiosity-driven computational model. In The Sixth Joint IEEE International Conference on Development and Learning and Epigenetic Robotics, Cergy-Pontoise, France (pp. 238-245) Retrieved from https://hal.archivesouverteshal-01384562.

Gal'perin, P. J. (1980). Zu grundfragen der psychologie [On basic questions of psychology]. Berlin, Germany: Pahl-Rugenstein.

Göncü, A., Mistry, J., \& Mosier, C. (2000). Cultural variations in the play of toddlers. International Journal of Behavioral Development, 24(3), 321-329. https://doi.org/10.1080/01650250050118303.

Halliday, M. A. K. (2006). Language of early childhood (Vol. 4). London, UK: Continuum.

Horner, V., \& Whiten, A. (2005). Causal knowledge and imitation/emulation switching in chimpanzees (Pan troglodytes) and children (Homo sapiens). Animal Cognition, 8(3), 164-181. https://doi.org/10.1007/ s10071-004-0239-6.

Hutt, C. (1966). Exploration and play in children. In J. S. Brunner, A. Jolly, \& K. Sylva (Eds.), (1967), Play: Its role in development and evolution (pp. 327-350). Harmondsworth, UK: Penguin.

Inhelder, B. (1971). The sensorimotor origins of knowledge. In D. N. Walcher \& D. L. Peters (Eds.), Early childhood: The development of self-regulatory mechanisms (pp. 142-156). New York, NY: Academic Press.

Kaduson, H. G. (2015). Play therapy across the life span: Infants, children, adolescents, and adults. In K. J. O’Connor, C. E. Schaefer, \& L. D. Braverman (Eds.), Handbook of play therapy (pp. 327-342). Hoboken, NJ: Wiley.

Karasik, L. B., Tamis-Lemonda, C. S., \& Adolph, K. E. (2011). Transition from crawling to walking and infants' actions with objects and people. Child Development, 82(4), 1199-1209. https://doi.org/10.1111/j.14678624.2011.01595.x.

Karpov, Y. V. (2003). Development through the lifespan-A neo-Vygotskian approach. In A. Kozulin, B. Gindis, V. S. Ageyev, \& S. M. Miller (Eds.), Vygotsky's educational theory in cultural context (pp. 138155). Cambridge, MA: Cambridge University Press.

Karpov, Y. V. (2005). The neo-Vygotskian approach to child development. Cambridge, MA: Cambridge University Press.

Kultti, A., \& Pramling, N. (2015). Bring your own toy: Socialisation of two-year-olds through tool-mediated activities in an Australian early childhood education context. Early Childhood Education Journal, 43(5), 367-376. https://doi.org/10.1007/s10643-014-0662-5.

Legare, C. H., \& Nielsen, M. (2015). Imitation and innovation: The dual engines of cultural learning. Trends in Cognitive Sciences, 19(11), 688-699. https://doi.org/10.1016/j.tics.2015.08.005.

Leont'ev, A. N. (1965). Problemy razvitiya psikhi [Problems of psychological development]. Moscow, Russia: Mysl'.

Leont'ev, A. N. (1978). Activity, consciousness, and personality. Englewood Cliffs, NJ.: Prentice-Hall.

Leont'ev, A. N. (1981). The problem of activity in psychology. In J. V. Wertsch (Ed.), The concept of activity in Soviet psychology (pp. 37-71). Armonk, NY: Sharpe. (Original work published in 1972).

Lewin, K. (1931). Environmental forces in child behavior and development. In C. Murchison (Ed.), The international university series in psychology. A handbook of child psychology (pp. 94-127). Worcester, MA: Clark University Press.

Libertus, K., Joh, A. S., \& Needham, A. W. (2015). Motor training at 3 months affects object exploration 12 months later. Developmental Science, 19(6), 1058-1066. https://doi.org/10.1111/desc.12370. 
Lockman, J. J. (2000). A perception-action perspective on tool use development. Child Development, 71(1), 137-144. https://doi.org/10.1111/1467-8624.00127.

Lockman, J. J., \& McHale, J. P. (1989). Object manipulation in infancy. In J. J. Lockman \& N. L. Hazen (Eds.), Action in social context. Perspectives in developmental psychology (pp. 129-167). Boston, MA: Springer.

Lourenço, O. M. (2016). Developmental stages, Piagetian stages in particular: A critical review. New Ideas in Psychology, 40, 123-137. https://doi.org/10.1016/j.newideapsych.2015.08.002.

Matusov, E., \& Hayes, R. (2000). Sociocultural critique of Piaget and Vygotsky. New Ideas in Psychology, $18(2-$ 3), 215-239. Retrieved from www.elsevier.com/locate/newideapsych.

Nielsen, M. (2012). Imitation, pretend play, and childhood: Essential elements in the evolution of human culture? Journal of Comparative Psychology, 126(2), 170-181. https://doi.org/10.1037/a0025168.

Nielsen, M., Tomaselli, K., Mushin, I., \& Whiten, A. (2014). Exploring tool innovation: A comparison of Western and Bushman children. Journal of Experimental Child Psychology, 126, 384-394. https://doi.org/ 10.1016/j.jecp.2014.05.008.

Oudgenoeg-Paz, O., Leseman, P. P., \& Volman, M. C. J. M. (2015). Exploration as a mediator of the relation between the attainment of motor milestones and the development of spatial cognition and spatial language. Developmental Psychology, 51(9), 1241-1253. https://doi.org/10.1037/a0039572.

Oudgenoeg-Paz, O., Volman, M. C., \& Leseman, P. P. (2016). First steps into language? Examining the specific longitudinal relations between walking, exploration and linguistic skills. Frontiers in Psychology, 7, 1458. https://doi.org/10.3389/fpsyg.2016.01458.

Pellegrini, A. D. (2009). Children's use of objects in exploration, in play, and as tools. In A. D. Pellegrini (Ed.), The role of play in human development (pp. 114-135). Oxford, UK: Oxford University Press.

Pellegrini, A. D. (2013). Object use in childhood: Development and possible functions. Behaviour, 150(8), 813843. https://doi.org/10.1163/1568539X-00003086.

Pellegrini, A. D., \& Bjorklund, D. F. (2004). The ontogeny and phylogeny of children's object and fantasy play. Human Nature 15(1), 23-43.

Pellegrini, A. D., \& Gustafson, K. (2005). Boys' and girls' uses of objects for exploration, play, and tools in early childhood. In A. D. Pellegrini \& P. K. Smith (Eds.), The nature of play: Great apes and humans (pp. 113138). New York, NY: Guilford Press.

Pellegrini, A. D., \& Hou, Y. (2011). The development of preschool children's (Homo sapiens) uses of objects and their role in peer group centrality. Journal of Comparative Psychology, 125(2), 239-245. https://doi.org/ $10.1037 / \mathrm{a} 0023046$.

Pellegrini, A. D., Dupuis, D., \& Smith, P. K. (2007). Play in evolution and development. Developmental Review, 27(2), 261-276. https://doi.org/10.1016/j.dr.2006.09.001.

Piaget, J. (1962). Play, dreams and imitation in childhood. New York, NY: Norton.

Piaget, J. (1967). Mastery play. In J. S. Bruner, A. Jolly, \& K. Sylva (Eds.), Play: Its role in development and evolution. Harmondsworth, UK: Penguin (Reprinted from Play, dreams and imitation in childhood, by J. Piaget, 1951, Routledge \& Kegan Paul).

Piaget, J. (1970). Piaget's theory. In B. Inhelder, H. H. Chipman, \& C. Zwingmann (Eds.), (1976), Piaget and his school: A reader in developmental psychology (pp. 11-23). New York, NY: Springer-Verlag.

Podd'jakov, N. N. (1979). Probeerhandelingen in het sensomotorische leren [Trial actions in sensorimotor learning]. Pedagogische Studiën, 56, 460-470. Retrieved from: http://pedagogischestudien.nl/home

Power, T. G. (2000). Play and exploration in children and animals. Mahwah, NJ: Psychology Press.

Riede, F., Johannsen, N. N., Högberg, A., Nowell, A., \& Lombard, M. (2018). The role of play objects and object play in human cognitive evolution and innovation. Evolutionary Anthropology, 27(1), 46-59. https:// doi.org/10.1002/evan.21555.

Rubin, K. H., Fein, G. G., \& Vandenberg, B. (1983). Play. In P. H. Mussen \& E. M. Hetherington (Eds.), Handbook of child psychology (Vol. 4, pp. 693-774). Hoboken, NJ: Wiley.

Ruiz, A. M., \& Santos, L. R. (2013). Understanding differences in the way human and non-human primates represent tools: The role of teleological-intentional information. In C. M. Sanz, J. Call, \& C. Boesch (Eds.), Tool use in animals: Cognition and ecology (pp. 119-133). Cambridge, UK: Cambridge University Press.

Smilansky, S. (1968). The effects of sociodramatic play on disadvantaged preschool children. New York, NY: John Wiley and Sons.

Smith, P. K., \& Pellegrini, A. (2008). Learning through play. In R.E. Tremblay, M. Boivin, \& R. D. V Peters (Eds.), Encyclopedia on early childhood development (pp. 1-6). Montreal, Quebec: Centre of Excellence for Early Childhood Development and Strategic Knowledge Cluster on Early Child Development. Retrieved from http://www.child-encyclopedia.com/documents/Smith-PellegriniANGxp.pdf.

Soska, K. C., \& Adolph, K. E. (2014). Postural position constrains multimodal object exploration in infants. Infancy, 19(2), 138-161. https://doi.org/10.1111/infa.12039.

Sutton-Smith, B. (1966). Piaget on play: A critique. Psychological Review, 73(1), 104-110. 
Tamis-LeMonda, C. S., \& Bornstein, M. H. (1994). Specificity in mother-toddler language-play relations across the second year. Developmental Psychology, 30(2), 283-292. https://doi.org/10.1037/0012-1649.30.2.283.

Tamis-LeMonda, C. S., Kuchirko, Y., \& Tafuro, L. (2013). From action to interaction: Infant object exploration and mothers' contingent responsiveness. IEEE Transactions on Autonomous Mental Development, 5(3), 202-209. https://doi.org/10.1109/TAMD.2013.2269905.

Thompson, B. N., \& Goldstein, T. R. (2019). Disentangling pretend play measurement: Defining the essential elements and developmental progression of pretense. Developmental Review, 52, 24 41. https://doi.org/10. 1016/j.dr.2019.100867.

Tomasello, M. (1999). The cultural origins of human cognition. Cambridge, MA: Harvard University Press.

Tomasello, M. (2003). Constructing a language: A usage-based theory of language acquisition. Cambridge, MA: Harvard University Press.

Tomasello, M. (2019). Becoming human: A theory of ontogeny. Cambridge, MA: Belknap Press.

Van Oers, B. (2010). Leermomenten in het manipulerend spelen van peuters en kleuters. Een onderwijspedagogische benadering [Young children's learning during manipulative play]. Tijdschrift voor Orthopedagogiek, 49, 503-513.

Van Oers, B. (2011). Where is the child? Controversy in the neo-Vygotskian approach to child development. Mind, Culture, and Activity, 18(1), 84-88. https://doi.org/10.1080/10749030903311985.

Van Oers, B. (2012). Developmental education for young children. Concept, practice and implementation. Dordrecht, the Netherlands: Springer.

Van Oers, B. (2013). Is it play? Towards a reconceptualisation of role play from an activity theory perspective. European Early Childhood Education Research Journal, 21(2), 185-198. https://doi.org/10.1080/ 1350293X.2013.789199.

Van Parreren, C. F. (1971). Psychologie van het leren [The Psychology of Learning]. Deventer, the Netherlands: van Loghum Slaterus

van Schijndel, T. J., Singer, E., van der Maas, H. L., \& Raijmakers, M. E. (2010). A sciencing programme and young children's exploratory play in the sandpit. European Journal of Developmental Psychology, 7(5), 603-617. https://doi.org/10.1080/17405620903412344.

Vandenberg, B. (1978). Play and development from an ethological perspective. American Psychologist, 33(8), 724-738.

Vig, S. (2007). Young children's object play: A window on development. Journal of Developmental and Physical Disabilities, 19(3), 201-215. https://doi.org/10.1007/s10882-007-9048-6.

Vygotsky, J. S. (1967). Play and its role in the mental development of the child. In J. S. Brunner, A. Jolly, \& K. Sylva (Eds.), Play: Its role in development and evolution (pp. 863-895). Harmondsworth, UK: Penguin (Reprinted from Soviet Psychology, 12(6), pp. 62-76, by J. S. Vygotsky, 1933, Leningrad: Hertzen Pedagogical Institute).

Weisberg, D. S., Hirsh-Pasek, K., Golinkoff, R. M., Kittredge, A. K., \& Klahr, D. (2016). Guided play: Principles and practices. Current Directions in Psychological Science, 25(3), 177-182. https://doi.org/10. 1177/0963721416645512.

Wyman, E., Rakoczy, H., \& Tomasello, M. (2009). Young children understand multiple pretend identities in their object play. British Journal of Developmental Psychology, 27(2), 385-404. https://doi.org/10.1348/ $026151008 X 322893$.

Yu, C., \& Smith, L. B. (2012). Embodied attention and word learning by toddlers. Cognition, 125(2), $244-262$. https://doi.org/10.1016/j.cognition.2012.06.016.

Publisher's Note Springer Nature remains neutral with regard to jurisdictional claims in published maps and institutional affiliations. 